\title{
Demand for labour inputs and adjustment costs: evidence from Spanish manufacturing firms
}

\author{
César Alonso-Borrego * \\ Universidad Carlos III de Madrid, Av. Madrid 126, E-28903 Getafe, Madrid, Spain
}

\begin{abstract}
This paper studies the structure of the adjustment costs for heterogeneous labour inputs, allowing for asymmetries and interaction effects among them. To do this, I estimate Euler equations for the demands of permanent nonproduction (white collar) and production (blue collar) employees using a sample of Spanish manufacturing firms. These equations are estimated using the subsample of observations for which adjustment is done, controlling for endogenous sample selection. The main results confirm the heterogeneity of adjustment costs for these two labour inputs, and the existence of cross-adjustment effects between them. Weak evidence of asymmetry in permanent nonproduction labour is also found.
\end{abstract}

JEL classification: C33; J23; J32

Keywords: Labour demand; Heterogeneous labour; Adjustment costs; Panel data

\section{Introduction}

Labour market regulations aimed at enhancing job-security are dominant in most western European countries, and Spain is not an exception. These regulations seek to reduce dismissals of workers and fluctuations in employment, and their effectiveness materialize through changes in the costs of adjustment. To understand how these job-security regulations operate it is therefore necessary to learn

\footnotetext{
* Tel.: + 34-916249749; Fax: + 34-916249875; E-mail: alonso1@eco.uc3m.es
}

0927-5371/98/\$19.00

PII: S0927-5371(98)00011-6 
how these costs affect labour demand and how such regulations modify them. As stressed by Hamermesh and Pfann (1996), knowledge of the structure of adjustment costs is crucial to understand macroeconomic fluctuations in employment.

Most empirical studies (e.g. Nadiri and Rosen, 1969; Sargent, 1978) presume that the quasi-fixity of labour results from increasing costs of adjustment. Nevertheless, the sources of such costs can be very different depending on whether changes in a firm's employment are either positive (hiring costs) or negative (firing costs), so that in general adjustment costs will depend on the sign of such adjustment. In fact, the standard assumption of quadratic and symmetric adjustment costs yields an unsatisfactory description of the costs that firms face when adjusting employment. Empirically, the dynamics of labour demand based on symmetric adjustment costs are in general at odds with the data. The rejection is stronger as the level of data disaggregation rises (e.g. from industry to firm). Using data on Dutch manufacturing firms, Pfann and Verspagen (1989) obtain evidence in favour of asymmetric adjustment costs, in which hiring costs exceed firing costs.

Moreover, the assumption of workers' homogeneity becomes inappropriate and may lead to wrong inferences if the dynamics of adjustment among labour inputs prove to be different. Intuitively, one would expect hiring costs to be larger the higher the skill of workers, since training costs are expected to be lower for unskilled labour. Furthermore, since severance pay depends on the worker's earnings and they depend on his skill, firing costs will increase with worker's skill. Empirical findings by Palm and Pfann (1990) and Pfann and Palm (1993), using aggregate data from the Netherlands and the UK, and Bresson et al. (1991, 1992), using firm-level data from France, among others, show that the adjustment speed of unskilled workers is generally higher than that of skilled workers. These studies seem to imply that when firms face a shock, they do not necessarily adjust employment uniformly for the different labour inputs.

Recognizing labour heterogeneity requires examining how the costs of changing one type of labour affect the dynamics of the demand for other types. After the occurrence of a shock, the speed of adjustment will not be the same for all labour inputs. A particular labour input will be adjusted more slowly than others if either its variable adjustment costs are more convex or, alternatively, they are simply greater and firms do not know the duration of the shock. Furthermore, the size of the shock that it is needed to adjust a given labour input increases with the fixed costs of adjusting that input. Additionally, stickiness in adjusting one type of labour may affect the speed at which other types are adjusted. In recent work, Rota (1997) finds considerable stickiness in Italian manufacturing employment, as reflected by the significant percentage of firms that do not adjust employment in a particular year. This sort of evidence suggests the existence of a significant lump-sum component in firms' adjustment costs.

The main purpose of this paper is to evaluate the structure of adjustment costs considering different labour inputs, and allowing for interrelated dynamics among 
them, ${ }^{1}$ and for costs asymmetries between positive and negative employment changes. To do this, I use a Spanish panel of manufacturing firms corresponding to the period 1986-1991. This data set contains annual firm-level information on the number of employees by duration of the labour contract (fixed-term vs. indefinite) and by job (nonproduction or white collar workers vs. production or blue collar workers). I derive and estimate Euler equations for permanent production and nonproduction employees in a standard profit-maximizing framework, using an asymmetric adjustment costs representation. In the sample, there is evidence of a mass point at zero adjustment for each of the labour inputs, which suggests the existence of either fixed costs of adjustment, or indivisibilities in labour inputs, or both. Since the Euler equations are marginal conditions, they are inconsistent with a mass point at zero adjustment, and I therefore will estimate each equation using the subsample of observations for which adjustment is done, yet controlling for endogenous sample selection. I thus will concentrate in the adjustment costs structure that firms face in addition to fixed costs; although my approach recognizes (and controls for) the possibility of such fixed costs, I will not consider their estimation.

The Spanish case is an interesting one, because the regulations underlying its labour market, which lie on the same job-security principles as those of most western European countries (see Burda, 1991), are also among the most protective. These regulations have been characterized by the existence of mandatory severance payments, which increase firing costs leading in practice to (quasi) permanent labour contracts, and reducing fluctuations in employment at the expense of greater lags in its adjustment. In addition, as Blanchard et al. (1995) remark, the microeconomic aspects of the Spanish labour market, and in particular its labour market institutions and regulations, 'make the Spanish market one of the most rigid in the industrialized world'. Before 1984, the labour market legislation only allowed for permanent employment contracts, which entailed restrictive conditions for layoffs and sizeable redundancy payments. Since 1984, restrictions on fixedterm or temporary contracts have been gradually eliminated. New labour regulations allowed firms to offer workers temporary contracts for jobs that were not temporary in nature, ${ }^{2}$ and to dismiss workers with temporary contracts and low

\footnotetext{
1 Pindyck and Rotemberg (1983) estimate a system of factor demands using US aggregate manufacturing data, but they assume that the effects of changes in one factor on costs of adjusting other factors are zero, so cross effects in their model appear solely through technology.

${ }^{2}$ Before 1984, temporary contracts were allowed just for seasonal jobs, related to agriculture, construction and tourism activities. Since then, the number of temporary contracts lived a huge increase. The share of temporary employment in Spain rose from $10 \%$ in the whole economy and $2 \%$ in manufacturing in 1983 to $33 \%$ in the whole economy and $10 \%$ in manufacturing in 1993 . In the period 1986-1990, 80\% of the contracts registered at employment offices were temporary. For a complete description of the typology of temporary contracts in Spain and their effects, see Segura et al. (1991).
} 
redundancy payments (relative to those for permanent workers, that is, workers with indefinite contracts). These reforms entailed a significant increase in the share of temporary employees in total employment, though strong regulations on permanent employment were maintained. In previous work, Sanz Gómez (1993) found that permanent production workers have been strongly substituted for by temporary workers. The extensive use of temporary contracts in Spain since the mid-80s has shaped a dualistic labour market, where labour turnover is high for temporary workers, but very low for permanent ones. The Spanish data set used in this paper allows us to consider differences in adjustment costs and cross-adjustment effects for three different labour inputs: permanent nonproduction workers, permanent production workers and temporary workers.

The rest of this paper is organized as follows. The basic model is presented in Section 2. Section 3 summarizes the characteristics of the data set and the sample period for which the data are available, and discusses the econometric approach. The estimation results are presented in Section 4. Section 5 gathers the main implications of the empirical analysis and concludes.

\section{A dynamic model of labour inputs demands}

Each firm is assumed to maximize the expected discounted value of its stream of current and future real profits. Every period $t$, a firm chooses inputs of permanent nonproduction or white collar workers $\left(L_{t}^{1}\right)$, permanent production or blue collar workers $\left(L_{t}^{2}\right)$, and temporary workers $\left(L_{t}^{3}\right)$, and uses capital $K_{t}$ (assumed to be predetermined). ${ }^{3}$ Therefore, the problem for the firm can be written as:

$$
\max _{\left\{L_{t}^{j}\right\}_{j=1}^{3}} E_{t} \sum_{s=0}^{\infty} \rho_{t+s}\left[F\left(L_{t+s}, K_{t+s}\right)-\mathrm{AC}\left(L_{t+s}, L_{t+s-1}\right)-\sum_{j=1}^{3} W_{t+s}^{j} L_{t+s}^{j}\right]
$$

where $E_{t}[\cdot]=E\left[\cdot \mid \Omega_{t}\right]$ denotes the mathematical expectation given the information set available to the firm when choosing labour inputs at period $t, \Omega_{t} ; F(\cdot)$ is the production function, which depends on the vector of labour inputs, $L_{t}=\left(L_{t}^{1}, L_{t}^{2}\right.$, $\left.L_{t}^{3}\right)^{\prime}$, and the real capital stock $K_{t}$; and $W_{t}^{j}$ is the real wage paid to labour input $j$, $L_{t}^{j}$. The function $\mathrm{AC}(\cdot)$ represents adjustment costs (measured in output units), which is defined in terms of the growth rates of labour inputs, that is, $\operatorname{AC}\left(L_{t}\right.$, $\left.L_{t-1}\right)=\mathrm{AC}\left(\Delta \ln L_{t}\right)$, where $\Delta$ denotes the first-differences operator. Notice that

\footnotetext{
${ }^{3}$ This simplifying assumption, which is equivalent to assuming that adjustment costs for capital are not interrelated with labour inputs, might be relaxed by introducing cross-adjustment terms for capital in the adjustment cost function. I rule out this possibility in order to minimize the number of parameters to estimate.
} 
the specification of adjustment costs in terms of the growth rates takes into account the relative sizes of firms, implying that for a given percentage change in labour input, adjustment costs are equal among firms with different size.

Thus, the maximization problem above yields the following first-order conditions (Euler equations) for each labour input $j$ :

$$
E_{t}\left[\frac{\partial F_{t}}{\partial L_{t}^{j}}-W_{t}^{j}-\frac{1}{L_{t}^{j}}\left(\frac{\partial \mathrm{AC}\left(\Delta \ln L_{t}\right)}{\partial \Delta \ln L_{t}^{j}}-\rho_{t+1} \frac{\partial \mathrm{AC}\left(\Delta \ln L_{t+1}\right)}{\partial \Delta \ln L_{t+1}^{j}}\right)\right]=0 .
$$

To get explicit forms for the Euler equations, it is necessary to adopt parameterizations of the technology and the adjustment cost function. For the technology $Y_{t}=F(\cdot)$, I assume a Cobb-Douglas specification in terms of the efficiency units of labour and capital,

$$
Y_{t}=\exp \left(e_{t}\right) K_{t}^{\alpha_{K}}\left(\sum_{j} \lambda^{j} N_{t}^{j}\right)^{\alpha_{L}},
$$

where $e_{t}$ denotes technological shocks, $N_{t}^{j}$ represents labour input $j$ in annual units, ${ }^{4}$ and $\lambda^{j}(j=1,2,3)$ measures the relative productivity of input $j, N_{t}^{j}$, where $\lambda^{1}$ is normalized to unity. Therefore, the marginal productivity for labour input $j$ can be written as

$$
\frac{\partial F_{t}}{\partial L_{t}^{j}}=\frac{\partial F_{t}}{\partial N_{t}^{j}} \frac{\mathrm{d} N_{t}^{j}}{\mathrm{~d} L_{t}^{j}}=\left(\alpha_{L} \lambda^{j}\right) \frac{Y_{t}}{\sum_{j} \lambda^{j} N_{t}^{j}} \frac{\mathrm{d} N_{t}^{j}}{\mathrm{~d} L_{t}^{j}} .
$$

The specification for adjustment costs allows for asymmetries between firing and hiring costs, so that the cost of a positive percentage change is allowed to differ from the cost of a negative percentage change of the same size. Furthermore, I allow for cross-adjustment effects among different labour inputs. The empirical specification for adjustment costs is a third degree polynomial in terms of the growth rates of labour inputs: ${ }^{5}$

$$
\begin{aligned}
\operatorname{AC}\left(\Delta \ln L_{t}\right)= & \frac{1}{2} \sum_{m} \gamma_{m m}\left(\Delta \ln L_{t}^{m}\right)^{2}+\frac{1}{3} \sum_{m} \delta_{m}\left(\Delta \ln L_{t}^{m}\right)^{3} \\
& +\sum_{m} \sum_{s \neq m} \gamma_{m s}\left(\Delta \ln L_{t}^{m}\right)\left(\Delta \ln L_{t}^{s}\right)
\end{aligned}
$$

where asymmetry between hiring and firing costs arises whenever $\delta_{j} \neq 0$ : hiring costs will be higher (resp. lower) than firing costs if $\delta_{j}>0$ (resp. $\delta_{j}<0$ ). The

\footnotetext{
${ }^{4}$ That is, whereas for permanent labour inputs $(j=1,2), N_{t}^{j}=L_{t}^{j}$, for the temporary labour input $N_{t}^{3}=L_{t}^{3} \times($ average number of weeks worked during the year) $/ 52$.

${ }^{5}$ This polynomial can be viewed as a Taylor approximation to more general nonlinear forms of adjustment cost functions, as it is the case for the asymmetric adjustment cost specification in Pfann and Verspagen (1989), Bresson et al. (1991) and Pfann and Palm (1993).
} 
coefficients $\gamma_{j k}$ capture possible interactions among adjustments in different labour inputs. These interaction effects can appear due to changes in the composition of the labour force that may entail disruption effects in the organization of the production process. The costs associated with such disruption effects after a change in a particular labour input could be affected if the remaining labour inputs are adjusted accordingly. For example, let $\gamma_{j k}>0$ (resp. $\left.\gamma_{j k}<0\right)$; after a decrease in input $j\left(\Delta \ln L_{t}^{j}<0\right)$, adjustment costs may be reduced if $\Delta \ln L_{t}^{k}>0$ (resp. $\Delta \ln L_{t}^{k}<0$ ). Whereas the main source of asymmetry for each $j$-th input comes through $\delta_{j}$, the coefficients $\gamma_{j k}$ only have a marginal impact on the asymmetry between hiring and firing costs; their main effects concern the convexity curvature of the adjustment cost function.

I will concentrate on the estimation of the Euler equations for permanent nonproduction and production labour inputs, and I will not consider the equation for temporary workers. The main reason, that will be justified in detail below, is that the frequency of adjustments in temporary employees during the year is very high, and therefore it is very difficult to capture the adjustment costs structure for these workers using annual data.

\section{Data and econometric issues}

\subsection{Data sources}

The main data set is a balanced panel of 1080 manufacturing firms recorded in the database of the Central de Balances del Banco de España (Central Balance Sheet Office, after this, CBBE) during the period 1986-1991 (see Appendix A for a description of these data). Data on three categories of employment are available: permanent employees, which are broken down by occupation into nonproduction or white collar workers and production or blue collar employees; and temporary employees. Unfortunately, no breakdown by occupation exists for temporary employees. Finally, another limitation of the data is that there is no information on fires and hires, so it is only possible to measure net changes (through variations in the stocks of labour inputs), but not gross changes in labour inputs. ${ }^{6}$ Consequently, all the dynamics that can be captured when estimating the model will be based on net changes in employment.

Even though the CBBE data include information on the firm's average wage rate for its labour force (firm's labour costs/number of employees), the firm's wage rate for each labour input is not reported. Complementary data on wages are

\footnotetext{
${ }^{6}$ This problem is more acute the higher the level of aggregation in employment, so hopefully disaggregation of employees by occupation and type of contract will reduce the difference between net and gross changes.
} 
obtained from the Encuesta de Salarios (Wage Survey, source: National Statistics; ES after this) and from Distribución Salarial en España (Wage Distribution in Spain, source: National Statistics; DS after this). The ES survey provides industry-level information about average wages for production and nonproduction employees per year, irrespective of contract duration. In order to distinguish the wage rates of temporary and permanent employees, I use the DS survey, which unfortunately reports industry level information just for 1988. It will thus not be possible to capture any time variation of relative wages between temporary and permanent employees.

\subsection{Preliminary evidence}

Value added in Spanish manufacturing registered an annual average growth rate of $3.9 \%$ during the period 1986-1990. Employment in this sector grew accordingly at an average annual rate of $2.7 \%$. In the earlier expansionary period (1966-1974), an annual growth rate of $9.1 \%$ in manufacturing value added led to a $3.4 \%$ employment growth. This greater elasticity of employment to GDP growth in the eighties is partly explained by the greater flexibility of the Spanish labour market after the introduction of temporary contracts, which have contributed to reducing employment persistence (cf. Bentolila and Dolado, 1994). The share of temporary employment in Spanish manufacturing has risen monotonically from 1986 to 1990 . Table 1 shows the evolution over time of the main variables related

Table 1

Descriptive statistics (weighted averages)

\begin{tabular}{|c|c|c|c|c|c|c|}
\hline \multirow[t]{2}{*}{$\%$} & \multicolumn{6}{|l|}{ Year } \\
\hline & 1986 & 1987 & 1988 & 1989 & 1990 & 1991 \\
\hline \multicolumn{7}{|l|}{ Rates of growth } \\
\hline Real output & & 8.28 & 7.83 & 7.82 & 0.06 & 0.04 \\
\hline Employment & & 1.65 & 1.88 & 1.87 & -0.82 & -2.21 \\
\hline Permanent & & 0.41 & 0.32 & -0.33 & -1.41 & -1.75 \\
\hline Nonproduction & & 1.91 & 1.89 & 1.52 & 1.60 & 0.83 \\
\hline Production & & -0.37 & -0.51 & -1.32 & -3.10 & -3.26 \\
\hline Temporary & & 22.82 & 23.50 & 26.70 & 4.41 & -6.04 \\
\hline Wages & & 9.23 & 6.26 & 7.09 & 9.72 & 8.98 \\
\hline Investment rate & & 6.06 & 6.81 & 6.81 & 7.63 & 7.44 \\
\hline Net investment rate & & 1.76 & 2.47 & 2.29 & 2.79 & 2.31 \\
\hline \multicolumn{7}{|c|}{ Labour shares (in percentage of total employment) } \\
\hline Permanent & 94.45 & 93.28 & 91.85 & 89.87 & 89.33 & 89.75 \\
\hline Nonproduction & 32.10 & 32.20 & 32.20 & 32.10 & 32.87 & 33.90 \\
\hline Production & 62.35 & 61.08 & 59.65 & 57.77 & 56.46 & 55.85 \\
\hline Temporary & 5.55 & 6.72 & 8.15 & 10.13 & 10.67 & 10.25 \\
\hline
\end{tabular}

Balanced panel 1986-1991 (1080 firms). 
to firms' activity in the sample. The most striking fact in this table is the different evolution of each of the labour inputs, which confirms that the assumption of homogeneous labour hides the differences in dynamics among labour inputs. Whereas both the absolute and the relative amount of permanent employees decreased along the period, temporary employment experienced a sharp growth from 1987 to $1990 .{ }^{7}$ Those years correspond to the expansionary phase of the cycle, with high growth rates in real output, which contrasts with the reduction in permanent employment during that period. This reduction is mainly led by permanent production employment: its share in total employment fell from $62.3 \%$ in 1986 to $55.8 \%$ in 1991 .

Table 2 reports for each labour input the sample frequencies of movements by year and size. The following conclusions can be drawn from examining this table. First, while the proportion of observations not adjusting temporary employment is very small, there is a significant proportion of firms that are not adjusting permanent employment. This pattern is similar as that found in Rota (1997) for Italy, a country also characterized by an extremely rigid labour market. Second, adjustments are much more infrequent for nonproduction workers, precisely those for whom training costs and severance payments are expected to be higher. Third, for any labour input, the larger the firm, the higher the probability of adjustment, which suggests either indivisibilities in labour inputs or, more likely, the existence of costs of adjustment which are fixed in amount per firm. For a given percentage change in a particular input, the cost per worker declines with firm size. ${ }^{8}$

I have also reported the average of the mean job duration of temporary employees, defined as the mean number of weeks divided by 52 . The figures suggest that many adjustments of temporary employment take place within the year. Given the annual frequency of the data, it is very difficult to capture most of the movements occurred in temporary employment. Even though adjustment costs for temporary workers may be non-negligible, we cannot identify them at annual frequencies, so that I will not consider the estimation of the Euler equation for this labour input.

\subsection{Econometric issues}

Even though the Euler Eq. (2) include unobserved expectations of forward variables, they can be substituted for by their actual values, adding an expectational error. Under rational expectations, and in the absence of measurement errors

\footnotetext{
${ }^{7}$ Even though the employment trend for this sample matches that for total manufacturing until 1991, the growth rates are significantly lower than the rate for total manufacturing employment in this period.

${ }^{8}$ On the basis of informal evidence, it seems that smaller firms make fewer adjustments in the number of employees, but they exploit more frequently the possibility of overtime hours. Unfortunately, the data set reports information on the number of employees, but not on hours effectively worked.
} 
Table 2

Firms' distribution of movements in labour inputs by year and by size

\begin{tabular}{|c|c|c|c|c|c|c|c|}
\hline \multirow[t]{2}{*}{ Type of labour } & & \multirow[t]{2}{*}{ Movement } & \multicolumn{5}{|l|}{ Year } \\
\hline & & & 1987 & 1988 & 1989 & 1990 & 1991 \\
\hline \multirow[t]{6}{*}{ Permanent } & & Hiring & 42.96 & 43.80 & 41.02 & 36.20 & 34.54 \\
\hline & & Firing & 36.76 & 37.68 & 40.28 & 45.93 & 45.56 \\
\hline & Nonproduction & Hiring & 32.87 & 38.89 & 35.56 & 34.36 & 31.57 \\
\hline & & Firing & 21.48 & 21.02 & 24.16 & 25.93 & 26.58 \\
\hline & Production & Hiring & 37.87 & 38.71 & 37.96 & 33.06 & 31.67 \\
\hline & & Firing & 36.76 & 38.33 & 39.45 & 45.18 & 45.00 \\
\hline \multirow[t]{3}{*}{ Temporary } & & Hiring & 76.02 & 74.35 & 74.07 & 64.35 & 58.52 \\
\hline & & Firing & 19.44 & 20.65 & 20.74 & 30.46 & 35.09 \\
\hline & & Average job duration & 0.36 & 0.40 & 0.44 & 0.46 & 0.48 \\
\hline \multirow[t]{2}{*}{ Type of labour } & & Movement & Size & & & & \\
\hline & & & Small & Med1 & Med2 & Large & Total \\
\hline \multirow[t]{6}{*}{ Permanent } & & Hiring & 29.21 & 40.54 & 42.75 & 41.22 & 39.70 \\
\hline & & Firing & 26.45 & 35.56 & 44.95 & 53.76 & 41.24 \\
\hline & Nonproduction & Hiring & 18.81 & 26.74 & 41.17 & 47.56 & 34.63 \\
\hline & & Firing & 12.37 & 17.81 & 24.53 & 38.25 & 23.83 \\
\hline & Production & Hiring & 29.60 & 35.94 & 38.83 & 36.04 & 35.85 \\
\hline & & Firing & 23.16 & 34.33 & 45.29 & 55.82 & 40.95 \\
\hline \multirow[t]{2}{*}{ Temporary } & & Hiring & 71.45 & 71.39 & 70.10 & 64.87 & 69.46 \\
\hline & & Firing & 19.60 & 22.57 & 25.84 & 31.79 & 25.28 \\
\hline
\end{tabular}

Balanced panel 1986-1991 (1080 firms). The category 'no change' has been dropped for being redundant.

The average job duration of temporary employment is measured as the number of weeks divided by 52 .

The size variables are referred to the firm's time average of total employment.

Small denotes employment lower than or equal to 25 .

Med1 denotes employment between 25 and 75 .

Med2 denotes employment between 75 and 200 .

Large for employment larger than 200.

and macroeconomic shocks, this expectational error $\epsilon_{i, t+1}^{j}$ satisfies the orthogonality condition $E\left[\epsilon_{i, t+1}^{j} \mid \Omega_{i t}\right]=0$. However, while expectations of forward variables will be a function of variables in the information set $\Omega_{i t}$ (and thus orthogonal to the error term), actual values of variables dated $t+1$ will no longer be orthogonal to the error term. Therefore, OLS estimates will be inconsistent, and an instrumental variable approach will be needed. In principle any variable included in the information set will be a valid instrument. I will thus perform joint estimation of the system of Euler equations using the Generalized Method of Moments.

Since the wage rate for each labour input is observed at the industry level, but not at the firm level (at which only the total wage bill and the amount of the each of the labour inputs are observed), I will assume that the wage margins between any two labour inputs $j$ and $k, \mu_{i t}^{j, k}=W_{i t}^{j} / W_{i t}^{k}$, are equal between firms in the 
same industry. ${ }^{9}$ This assumption implies that if a firm pays to a certain labour input a wage rate above the industry wage rate, it also pays wages above the industry wage rate to the other labour inputs. This is partly consistent with Groshen (1991) for the US and, particularly, with Andrés and García (1991), for Spain, where firms that pay wages above the average in some category tend to pay wages above the average in all categories.

The wage measure $W_{i t}^{j}$ is expected to differ from the true wage $W_{i t}^{j *}$ by an error term. This error can be characterized by a time-invariant, firm-specific, measurement error component $\eta_{i}^{j *}$, plus an additional uncorrelated component $\zeta_{i t}^{j}$ reflecting further differences between the measured wage and the true wage. Hence, the observed and the true wages are related by the relation $W_{i t}^{j}=W_{i t}^{j *}+$ $\eta_{i}^{j *}+\zeta_{i t}^{j}$. The existence of a highly persistent component of the measurement error implied by $\eta_{i}^{j *}$ seems very plausible. For instance, if a firm pays a wage margin above the industry average to a certain input, the observed wage for this firm and this particular input will be downward biased. Since the relative wage for such input in such firm will be more likely to remain above the industry-level relative wage in subsequent periods, there will appear a persistently negative measurement error. Notice that some assumption about the measurement error structure, like the one I make, is necessary for model identification.

The unobservables in the empirical Euler equations are thus characterized by

$$
v_{i, t+1}^{j}=\eta_{i}^{j}+a_{t+1}^{j}+u_{i, t+1}^{j}, \quad j=1,2
$$

where, for input $j, \eta_{i}^{j}$ captures unobserved firm-specific time invariant effects (including time-invariant measurement errors in wages), $a_{t+1}^{j}$ is the aggregate shock in the demand for input $j$ at period $t+1$, and $u_{i, t+1}^{j}$ is an idiosyncratic term including expectational errors $\epsilon_{i, t+1}^{j}$, uncorrelated measurement errors $\zeta_{i t}^{j}$, and idiosyncratic shocks. The system must be estimated in first-differences to account for firm-specific fixed effects. To control for aggregate shocks affecting all firms equally, time dummies must also be included.

The fact that many firms do not adjust employment every year, as shown in Table 2, is inconsistent with a differentiable specification for adjustment costs, because there should not be any mass point for $\Delta \ln L_{i t}^{j}$. However, the Euler equation for input $j$ would still be valid for observations for which the adjustment is done. In such a case, the Euler equation for each of the permanent labour inputs can be estimated using those observations for which adjustment in two consecutive periods is accomplished. Hence, I will condition on the event $D_{i, t+1}^{j}=1\left(\Delta \ln L_{i t}^{j}\right.$ $\left.\Delta \ln L_{i, t+1}^{j} \neq 0\right)=1$, where $1(\cdot)$ is the indicator function, which takes value one if

\footnotetext{
${ }^{9}$ Obviously, whereas the wage margin of labour input $j$ relative to labour input $k$ will be constant across firms in the same industry, the wage margin of a given labour input with respect to the average wage rate (total labour cost/total employment) will in general be different across firms, reflecting differences in the occupational structure of employment across firms.
} 
the condition is true and zero otherwise. Since sample selection depends on the variable of interest, endogeneity of selection must be accounted for.

Let $Z_{i t} \in \Omega_{i t}$ be a vector of valid instruments for the Euler equation in first differences, so that $E\left[\Delta v_{i, t+1}^{j} \mid Z_{i t}\right]=0$. However, since I am conditioning on the event $D_{i, t+1}^{j}=1$, in general $E\left[\Delta v_{i, t+1}^{j} \mid Z_{i t}, D_{i, t+1}^{j}=1\right] \neq 0$. The choice probability of $D_{i, t+1}^{j}=1$, or propensity score, conditional on $Z_{i t}$, can be written as $p_{i, t+1}^{j}=\operatorname{Pr}\left[\pi_{t+1}^{j \prime} Z_{i, t+1}+\xi_{i, t+1}^{j}>0\right]$, where $\pi_{t+1}^{j}$ is a parameter vector, and $\xi_{i, t+1}^{j}$ is an error term. If the $\xi_{i, t+1}^{j}$ are independently distributed with respect to $Z_{i t}$ (see Stoker, 1991), then the conditional expectation $E\left[\Delta v_{i, t+1}^{j} \mid Z_{i t}, D_{i, t+1}^{j}=1\right]$ can be obtained as a function of the $p_{i, t+1}^{j}$. Under certain conditions (see Amemiya, 1984), this conditional expectation can be written as $E\left[\Delta v_{i, t+1}^{j} \mid Z_{i t}, D_{i, t+1}^{j}=1\right]=$ $\sigma_{t+1}^{j} \phi_{i, t+1}^{j}$, where $\sigma_{t+1}^{j}$ is the covariance between $\Delta v_{i, t+1}^{j}$ and $\xi_{i, t+1}^{j}$ (normalized by the variance of $\xi_{i, t+1}^{j}$ ), and $\phi_{i, t+1}^{j}$ is a function of the $Z$ 's which, if $\xi_{i, t+1}^{j}$ is normally distributed, is the inverse of the Mills ratio. ${ }^{10}$ Therefore, defining $h_{i, t+1}^{j}(\theta)=\Delta v_{i, t+1}^{j}-\sigma_{t+1}^{j} \phi_{i, t+1}^{j}$, the following moment conditions for input $j$ hold for the subsample of observations for which the event $D_{i, t+1}^{j}=1$ occurs:

$$
E\left[h_{i, t+1}^{j}(\theta) \mid Z_{i t}, D_{i, t+1}^{j}=1\right]=E\left[\Delta v_{i, t+1}^{j}-\sigma_{t+1}^{j} \phi_{i, t+1}^{j} \mid Z_{i t}, D_{i, t+1}^{j}=1\right]=0 .
$$

Although the $\phi_{i, t+1}^{j}$ 's are unobservable, they can be substituted by consistent estimates based on reduced-form probit models for the propensity scores, and estimate the Euler equations in Eq. (7) by means of GMM procedures. Let $h_{i, t+1}(\theta)=\left[h_{i, t+1}^{1}(\theta), h_{i, t+1}^{2}(\theta)\right]^{\prime}$ be the stacked vector of Euler equations for both labour inputs. The GMM estimator exploits the sample analogues of the orthogonality conditions

$$
E\left[h_{i, t+1}(\theta) Z_{i t} \mid D_{i, t+1}^{j}=1\right]=0 .
$$

Denoting the vector of moment restrictions for every firm $i(i=1, \ldots, n)$ as $\Psi_{i}\left(x_{i}, \theta\right)=\left[\Psi_{i 1}^{\prime}, \ldots, \Psi_{i, T-1}^{\prime}\right]^{\prime}$, where $\Psi_{i t}(\theta)=h_{i, t+1}(\theta) Z_{i t}, \hat{\theta}_{\mathrm{GMM}}$ is the estimator that minimizes the quadratic form:

$$
\sum_{i} \Psi_{i}\left(x_{i}, \theta\right)^{\prime} A_{n} \sum_{i} \Psi_{i}\left(x_{i}, \theta\right)
$$

where $\mathbf{A}_{n}$ is a weighting matrix which, under some regularity conditions, can be chosen optimally using a consistent estimate of the covariance matrix of the moment restrictions. The cross-equation restrictions in the system of Euler equations induce non-linearities that require the use of numerical optimization (see Ogaki, 1993). The estimation was performed using routines written in GAUSS language and the optimization algorithm included in the GAUSS application

\footnotetext{
${ }^{10}$ The inverse of the Mills ratio is defined as the ratio of the density function to the cumulative distribution function of the standard normal variable, evaluated at $-\pi_{t+1}^{\prime} Z_{i t}$.
} 
module OPTMUM. I will compute two-step GMM estimates that take the weighting matrix $\mathbf{A}_{n}(\theta)$ based on the one-step GMM estimates.

\section{Estimation results}

For the estimation of the Euler equations I proceed in three stages. The main parameters of interest are the adjustment cost parameters. However, the Euler Eq. (2) include the values of the marginal productivities of the labour inputs, but they can be estimated separately using the parametric assumptions in Eq. (3), and substituted into each of the Euler equations in order to obtain the estimates of the adjustment cost parameters. In the estimation of the Euler equation for each of the labour inputs I use those observations for which the corresponding labour inputs are adjusted in two consecutive periods. In order to control for endogenous sample selection, I must first obtain consistent estimates of the propensity scores and substitute the estimated values $\hat{\phi}_{i, t+1}^{j}$ (and the technological parameters) into Eq. (7) to estimate the adjustment costs parameters using GMM procedures. ${ }^{11}$

\subsection{Estimation of the technology parameters}

The parameters of the production function can be identified separately, exploiting the information about inputs and the parameterization of technology in Eq. (3). I take a first order $\log$-linear approximation around $\lambda_{j}=1, \forall j$, which yields:

$$
\ln Y_{i t}=\alpha_{K} \ln K_{i t}+\alpha_{L} \ln N_{i t}+\left[\alpha_{L}\left(\lambda^{2}-1\right)\right] \frac{N_{i t}^{2}}{N_{i t}}+\left[\alpha_{L}\left(\lambda^{3}-1\right)\right] \frac{N_{i t}^{3}}{N_{i t}}+e_{i t}
$$

where $N_{i t}=\Sigma_{j} N_{i t}^{j}$. Denoting $\boldsymbol{X}_{i t}$ as the vector of explanatory variables and $\boldsymbol{\alpha}=\left(\alpha_{K}, \alpha_{L}, \alpha_{L}\left(\lambda^{2}-1\right), \alpha_{L}\left(\lambda^{3}-1\right)\right)^{\prime}$ as the parameter vector in Eq. (10), this equation can be written as $\ln Y_{i t}=\alpha^{\prime} \boldsymbol{X}_{i t}+e_{i t}$. The technological shock $e_{i t}$ combines time-invariant firm-specific effects, aggregate shocks and idiosyncratic shocks,

$$
e_{i t}=\mu_{i}+a_{t}^{y}+\nu_{i t}
$$

where the idiosyncratic shock $\nu_{i t}$, which entails technical progress, may be autocorrelated over time. I assume that $\nu_{i t}$ follows an $\operatorname{AR}(1)$ process, $\nu_{i t}=\rho \nu_{i, t-1}$ $+\epsilon_{i t}$. In this context, OLS estimation of Eq. (10) suffers from endogeneity bias

\footnotetext{
${ }^{11}$ The fact that $\phi_{i t}^{j}$ is replaced by a sample estimate introduces an additional error component which means that the conventional standard errors and specification tests will be inconsistent. However, obtaining consistent standard errors in this framework is a nontrivial task that is beyond the scope of the paper, and therefore I will not consider this problem.
} 
(cf. Griliches and Mairesse, 1998), since the endogenous variables in $\boldsymbol{X}_{i t}$ are correlated with $e_{i t}$. However, the model can be consistently estimated by means of a first-difference transformation that also takes account of the autocorrelated idiosyncratic shocks:

$$
\Delta \ln Y_{i t}=\rho \Delta \ln Y_{i, t-1}+\alpha^{\prime} \Delta X_{i t}+(-\rho \alpha)^{\prime} \Delta X_{i, t-1}+\tilde{a}_{t}^{y}+\Delta \epsilon_{i t}
$$

where the term that captures aggregate shocks is now $\tilde{a}_{t}^{y}=\Delta a_{t}^{y}-\rho \Delta a_{t-1}^{y}$. In the estimation of Eq. (12), lagged values of the logarithm of inputs and real output dated $t-2$ and earlier are valid instruments. Notice that the technology parameters $\theta_{Y}=\left(\alpha_{K}, \alpha_{L}, \lambda^{2}, \lambda^{3}, \rho\right)^{\prime}$ do not enter linearly in Eq. (12). However, all the parameters in Eq. (12) are known functions of $\theta_{Y}$. Thus after estimating the parameters from this equation, I can recover the parameters of interest in $\theta_{Y}$ using a Minimum Distance procedure.

It is important to notice that the sample period was characterized by a huge increase in the amount of temporary employment, following the 1984 labour market reform, that eliminated legal restrictions on temporary contracts. This reform allowed firms to reorganize their workforce by substituting temporary for permanent employment, which explains the surprisingly high growth rates of temporary employment. To account for this phenomenon of substitution of the existing labour input (permanent employment) by the new labour input (temporary), I have also included two qualitative variables which indicate whether the firm is reducing its permanent employment, at $t$ and $t-1$. The inclusion of these qualitative variables yields more precise estimates.

Table 3 presents the estimation results. The first panel reports the GMM estimates, where the dependent variable is the logarithm of real value added, and time dummies interacted with industry dummies were included to account for industry shocks. In addition to the lagged values of the explanatory variables dated $t-2$ and earlier, I have also included lags of employment in the four occupations that integrate nonproduction employment (managers, professionals, clerical and commercial employees) dated $t-2$ and earlier. These additional instruments helped to improve the precision of the estimates. The validity of the instruments is confirmed by the low value of the test of overidentifying restrictions. Furthermore, the significance of the lagged dependent variable and the lagged inputs provides evidence in favour of autocorrelated shocks.

The bottom panel presents the minimum distance estimates of the parameters of interest. The $Q$ test shows that the restrictions are not rejected by the data. The values of the estimated coefficients on capital and aggregate labour do not reject constant returns to scale. These two coefficients, and the autocorrelation coefficient $\rho$, are estimated with much more precision than the $\lambda^{j}$ parameters. These parameters, which represent the relative productivity of permanent production and temporary employees with respect to permanent nonproduction employees, were always below one, and we find that $\lambda^{2}>\lambda^{3}$, although the difference between them is not significant. 
Table 3

Estimation of the production function

\begin{tabular}{lc}
\hline Explanatory variables & Dependent variable: $\ln Y_{t}$ \\
\hline First-differences GMM estimates of the linear approximation \\
$\ln Y_{t-1}$ & $0.6081(0.0628)$ \\
$\ln K_{t}$ & $0.4047(0.1418)$ \\
$\ln N_{t}$ & $0.6894(0.1499)$ \\
$N_{t}^{2} / N_{t}$ & $-0.3343(0.3220)$ \\
$N_{t}^{3} / N_{t}$ & $-0.2821(0.3115)$ \\
$\ln K_{t-1}$ & $-0.1242(0.0556)$ \\
$\ln N_{t-1}$ & $-0.3963(0.1402)$ \\
$N_{t-1}^{2} / N_{t-1}$ & $0.2504(0.2436)$ \\
$N_{t-1}^{3} / N_{t-1}$ & $0.1180(0.2781)$ \\
$1\left(\Delta\left(L_{t}^{1}+L_{t}^{2}\right)<0\right)$ & $0.1430(0.0521)$ \\
$1\left(\Delta\left(L_{t-1}^{1}+L_{t-1}^{2}\right)<0\right)$ & $-0.1640(0.0476)$ \\
Wald tests: & \\
Lagged variables & $102.8(0.00)$ \\
Industry and time dummies & $190.2(0.00)$ \\
$J$ test & $60.5(0.67)$ \\
& \\
Minimum distance estimates of the structural parameters & \\
$\alpha_{K}$ & $0.2020(0.0858)$ \\
$\alpha_{L}$ & $0.6577(0.1419)$ \\
$\lambda^{1}$ & 1.0000 \\
$\lambda^{2}$ & $0.6594(0.4681)$ \\
$\lambda^{3}$ & $0.6223(0.4394)$ \\
& Wald tests: \\
Joint significance of $\lambda^{2}, \lambda^{3}$ & $0.6157(0.0572)$ \\
test & \\
\hline & $0.69(0.41)$ \\
& $2.84(0.24)$ \\
& $3.5(0.47)$ \\
\hline
\end{tabular}

Sample period: 1989-1991 (1080 firms).

Linear equation includes time dummies interacted with industry dummies.

Heteroskedasticity-robust asymptotic standard errors in parentheses.

$J$ is the Hansen-Sargan test of overidentifying restrictions, asymptotically distributed under the null of validity of the restrictions as a $\chi^{2}$ with 66 d.f.

$Q$ is the value of the minimum distance criterion, asymptotically distributed as a $\chi^{2}$ with 4 d.f. (equal to the number of restrictions).

The $p$-values of the tests (significance levels above which the null hypothesis is rejected) are reported in parentheses.

\subsection{Estimation of the adjustment costs parameters}

I jointly estimate the Euler equations for both permanent labour inputs, nonproduction and production workers, but discard the equation for temporary employees. This input enters the Euler equations for permanent employment contemporaneously and is treated as endogenous. 
To control for sample selection in each of the Euler equations, I first estimate probit reduced forms for the event $D_{i, t+1}^{j}=1$ for each permanent labour input. In order to allow for conditional heteroskedasticity over time, probit estimations are carried out year by year. The resulting estimates for nonproduction and production employees from 1989 to 1991 are reported in Table 4. The goodness-of-fit of the equations, according to the percentage of correct predictions on the event $D_{i, t+1}^{j}=$ 1 , is between 59 and $85 \%$. The lagged labour input $j$ has a positive and significant effect on the probability of adjustment, but this effect changes over time. Furthermore, the size of the firm does not have significant effects. It is remarkable that the probability of adjusting one input increases if the firm did adjust such labour input $j$ in the past (irrespective of the sign of the adjustment), which suggests the existence of firm heterogeneity in the size of fixed costs. Finally, changes in the firm's output (which approximate idiosyncratic shocks) have very different effects on the different years: this variable is only significant in 1989, and the effect is larger for permanent production employees. I then estimate the inverse of the Mills' ratio, $\hat{\phi}_{i, t+1}^{j}$, for each observation with $D_{i, t+1}^{j}=1$ and include this variable in the corresponding Euler equation as an additional regressor. The coefficient of this variable differs every year to allow for generalized heteroskedasticity.

Under measurement errors in wages, and even assuming that these measurement errors are serially uncorrelated, only the values of predetermined variables dated $t-2$ and earlier are valid instruments. The instrument set for the Euler equation for each input includes values of changes in the three labour inputs lagged two and three periods, lagged values of average real productivities of labour inputs, and the real wage for that input lagged two periods. These variables are arranged to enter as they do in the levels specification of the Euler equation, which significantly improves the precision of the estimates. I also control for the degree of utilization of production factors using two-digit industry-level data on capacity utilization. The measure of the firms' real discount rate is the long term nominal interest rate deflated by the corresponding industry-level price indices (see Appendix A for a complete description of the variables).

Two-step estimates of the set of Euler equations for permanent labour inputs based on the adjustment costs parameterization (Eq. (5)) are reported in the first column of Table 5. The selectivity correction terms are jointly significant for both equations. Furthermore, the low value of the $J$ test of overidentifying restrictions shows the validity of the instruments. Nevertheless, it is worth mentioning that the precision of the parameter estimates is low. Parameters associated with quadratic terms are positive for both nonproduction workers $\left(\gamma_{11}\right)$ and production workers $\left(\gamma_{22}\right)$. Interestingly, the quadratic terms differ between both labour inputs, which confirms the heterogeneity of adjustment costs for different labour inputs. Particularly interesting is that $\gamma_{11}>\gamma_{22}$, consistent with the higher skill of nonproduction labour.

The cross-adjustment terms are positive and jointly significant, but the cross-adjustment effects with temporary labour $\left(\gamma_{13}\right.$ and $\left.\gamma_{23}\right)$ are not individually signifi- 
Table 4

Probit estimates for adjustment in permanent labour inputs $D_{i t}^{j}=1\left(\Delta L_{i t}^{j} \Delta L_{i, t-1}^{j} \neq 0\right), j=1,2$

\begin{tabular}{|c|c|c|c|c|c|c|}
\hline \multirow[t]{2}{*}{ Variable } & \multicolumn{3}{|c|}{ Nonproduction $\left(L_{i j}^{1}\right)$} & \multicolumn{3}{|c|}{ Production $\left(L_{i j}^{2}\right)$} \\
\hline & 1989 & 1990 & 1991 & 1989 & 1990 & 1991 \\
\hline $\ln \left(L_{i, t-2}^{1}\right)$ & $0.67(0.10)$ & $0.56(0.09)$ & $0.67(0.10)$ & $0.09(0.08)$ & $0.10(0.08)$ & $0.15(0.08)$ \\
\hline $\ln \left(L_{i, t-2}^{2}\right)$ & $-0.37(0.12)$ & $-0.19(0.11)$ & $-0.15(0.11)$ & $0.25(0.10)$ & $0.48(0.11)$ & $0.56(0.11)$ \\
\hline $\ln \left(L_{i, t-2}^{3}\right)$ & $0.19(0.09)$ & $0.09(0.09)$ & $0.14(0.09)$ & $0.05(0.09)$ & $0.10(0.09)$ & $-0.01(0.09)$ \\
\hline$L_{i, t-2}^{3} / L_{i, t-2}$ & $-1.02(0.84)$ & $0.86(0.80)$ & $-0.47(0.78)$ & $-1.14(0.76)$ & $-0.47(0.72)$ & $1.05(0.72)$ \\
\hline Med1 & $-0.06(0.32)$ & $0.11(0.28)$ & $0.12(0.31)$ & $0.14(0.22)$ & $-0.05(0.22)$ & $-0.07(0.22)$ \\
\hline Med2 & $0.26(0.40)$ & $0.30(0.37)$ & $0.45(0.39)$ & $0.25(0.31)$ & $0.01(0.31)$ & $-0.05(0.32)$ \\
\hline Large & $0.57(0.55)$ & $0.68(0.51)$ & $0.20(0.52)$ & $0.32(0.44)$ & $-0.42(0.45)$ & $-0.40(0.45)$ \\
\hline$\Delta \ln \left(L_{i, t-2}^{1}\right)$ & $0.17(0.27)$ & $0.73(0.29)$ & $0.15(0.32)$ & $-0.02(0.25)$ & $0.44(0.29)$ & $0.06(0.37)$ \\
\hline$\Delta \ln \left(L_{i, t-2}^{2}\right)$ & $0.48(0.34)$ & $0.29(0.36)$ & $-0.46(0.26)$ & $0.04(0.28)$ & $0.79(0.28)$ & $0.46(0.22)$ \\
\hline$\Delta \ln \left(L_{i, t-2}^{3}\right)$ & $-0.03(0.10)$ & $0.00(0.08)$ & $0.02(0.08)$ & $-0.07(0.08)$ & $0.12(0.07)$ & $-0.04(0.07)$ \\
\hline$\Delta \ln \left(Y_{i, t-2}\right)$ & $0.65(0.39)$ & $0.04(0.35)$ & $0.20(0.35)$ & $0.93(0.31)$ & $-0.33(0.31)$ & $0.19(0.31)$ \\
\hline $1\left(\Delta L_{i, t-2}^{1}>0\right)$ & $7.83(0.43)$ & $7.65(0.42)$ & $7.61(0.43)$ & $0.05(0.13)$ & $0.32(0.14)$ & $0.10(0.14)$ \\
\hline $1\left(\Delta L_{i, t-2}^{2}>0\right)$ & $0.14(0.20)$ & $0.21(0.18)$ & $-0.07(0.20)$ & $7.63(0.34)$ & $7.40(0.37)$ & $7.26(0.39)$ \\
\hline $1\left(\Delta L_{i, t-2}^{1}<0\right)$ & $7.65(0.44)$ & $7.40(0.43)$ & $7.57(0.43)$ & $0.01(0.15)$ & $0.19(0.15)$ & $0.01(0.15)$ \\
\hline $1\left(\Delta L_{i, t-2}^{2, t-2}<0\right)$ & $0.10(0.19)$ & $0.34(0.19)$ & $-0.32(0.19)$ & $7.48(0.35)$ & $7.50(0.38)$ & $7.52(0.39)$ \\
\hline
\end{tabular}


Table 5

GMM estimation of the system of Euler equations for permanent nonproduction and production workers; third-degree polynomial

\begin{tabular}{llrrr}
\hline Permanent nonproduction & $\gamma_{11}$ & $0.7323(0.3797)$ & $0.5146(0.3000)$ & $0.5062(0.2986)$ \\
& $\delta_{1}$ & $0.4631(0.5060)$ & $0.6601(0.4592)$ & $0.6531(0.4597)$ \\
Permanent production & $\gamma_{22}$ & $0.1771(0.3568)$ & $0.0687(0.0805)$ & $0.0696(0.0803)$ \\
& $\delta_{2}$ & $-0.1145(0.1798)$ & $0.0615(0.0916)$ & $0.0561(0.0891)$ \\
Cross-adjustment effects & $\gamma_{12}$ & $0.5698(0.2928)$ & $0.0671(0.1196)$ & \\
& $\gamma_{13}$ & $0.0341(0.0229)$ & & \\
& $\gamma_{23}$ & $0.0076(0.0162)$ & & \\
Wald tests of joint significance & & & $9.7(3)$ \\
Selectivity terms & & & $6.8(3)$ & \\
& nonproduction & $12.2(3)$ & $2.6(3)$ & $5.8(3)$ \\
Time dummies & production & $8.2(3)$ & $5.5(3)$ & $0.6(3)$ \\
& & & $2.6(3)$ & \\
Cross-adjustment effects & nonproduction & $7.9(3)$ & & $45.9(50)$ \\
& production & $2.8(3)$ & $45.8(49)$ & 0.64 \\
\hline test $(d . f)$. & All & $17.2(3)$ & 0.60 & \\
$p$-value & Temporary & $12.3(2)$ & & \\
\hline
\end{tabular}

Time dummies included in both equations.

Heteroskedasticity-robust asymptotic standard errors in parentheses.

$J$ is the Hansen-Sargan test of overidentifying restrictions, asymptotically distributed under the null of valid restrictions as a $\chi^{2}$ with as many degrees of freedom as the number of overidentifying restrictions.

The $p$-value is the significance level above which the null hypothesis is rejected.

cant, and their size is very small. The high value of $\gamma_{12}$ relative to the remaining cross-adjustment terms is somewhat surprising given the heterogeneity between production and nonproduction employees. This result implies that hiring costs of (permanent) nonproduction employees can be lowered if the firm dismisses production employees in the same period. This coefficient can possibly be capturing, in addition to cross-adjustment effects, the effect of a change towards technologies that are less intensive in production labour. The increase both in net fixed-capital investment and in the share of permanent nonproduction employment, as shown in Table 1, favours this explanation. The lack of significance of the cross adjustment effects with temporary labour can be partly attributed to the fact that many movements in temporary labour occur at frequencies higher than annual.

The asymmetry coefficient is positive for nonproduction workers $\left(\delta_{1}\right)$, suggesting that hiring costs exceed firing costs, and negative for production workers $\left(\delta_{2}\right)$, which suggests the opposite. Nevertheless, none of these coefficients are significant. The standard error of $\hat{\delta}_{2}$ is particularly high, and in fact the sign of this coefficient changes when the insignificant cross-adjustment effects are dropped. 
In addition, I considered an alternative adjustment cost specification, consisting of a second-order polynomial that allowed for different coefficients on the quadratic terms, depending on the sign of the adjustment. This specification, which is non-differentiable at $\Delta \ln L_{t}^{j}=0$, implies a non-monotonic dynamic behaviour. The proper estimation of the Euler equations would involve the evaluation of derivatives of index models, which makes estimation very cumbersome. Instead, I estimated the equations interacting the coefficients associated with positive and negative changes with their respective dummy variables. From the estimates (not reported here), the main qualitative results hold. Adjustment costs appear to be higher for permanent nonproduction workers and asymmetric in the sense that hiring costs exceed firing costs for permanent nonproduction workers. However, asymmetry is not significant and goes in the opposite direction for production workers. Finally, there are no significant cross-adjustment effects.

As Bresson et al. (1991) stress, one need not believe that estimates of the Euler equations give the global adjustment cost function. Such estimates are very dependent on the sample behaviour of employment and give only an indication of the local shape of this function. In particular, as Table 1 shows, with the sample period characterized by a huge increase in the number of temporary employees together with a fall in permanent production employees, the estimates here must be viewed as local.

\section{Conclusions}

In this study I have derived and estimated Euler equations for the demand of permanent nonproduction and production labour inputs in a dynamic optimization framework under rational expectations. To do this, the capital stock was taken as predetermined and temporary labour was included as a separate input to allow for interrelations with both permanent labour inputs. The specification of adjustment costs was formulated in terms of growth rates of employment to take into account the relative sizes of firms, allowing for asymmetries between hiring and firing and for cross-adjustments effects among different labour inputs. The empirical analysis was performed using a panel of 1080 Spanish manufacturing firms.

The main conclusions that can be drawn from the estimations are as follows. There is evidence of heterogeneity in adjustment costs between permanent labour inputs. There is a positive cross-adjustment effect between nonproduction and production labour inputs. This effect, in the context of the sample period (characterized by a bias towards technologies less intensive in production labour) implies that, at the margin, the costs of hiring permanent nonproduction employment may be lowered if the firm dismisses permanent production employees at the same time. The cross-adjustment effects with temporary labour are also positive, but such effects are small and nonsignificant. Although there is a hint of evidence 
of asymmetry between firing and hiring costs in permanent nonproduction labour, it is not conclusive, since these parameters are loosely estimated. Adjustment costs for nonproduction workers appear to be higher than those for production workers. Intuitively, this is a sensible result, because the firm-specific human capital requirements are expected to be higher the higher the skill.

The results need to be qualified for a number of reasons. Mainly, most of the limitations of this study are intrinsically linked to the limitations of the data. First, as asserted by Hamermesh (1993a,b) and Hamermesh and Pfann (1996), employment plans are likely to be revised more frequently than once a year. Use of data at annual frequencies can lead to incorrect inferences about the underlying structure of adjustment costs. ${ }^{12}$ Empirically, quarterly data seem to be more adequate. In fact, the frequency at which adjustments are made will be higher the higher the flexibility of the contract. Therefore, the incidence of this problem will be more acute in the case of temporary workers than in the case of permanent workers. This assertion is confirmed by the data: the probability of adjustment decreases both with the duration of the contract and with the skill, and decisions on temporary labour occur at frequencies higher than annual. This fact could explain the nonsignificance of the cross-adjustment effects on temporary labour.

Whereas the empirical analysis has taken the capital stock as predetermined, it is plausible that the decisions of investment and labour demand are interrelated. In such a case, the adjustment cost function could be augmented to include interactions between labour and capital inputs. However, the generalization to a more realistic model would pay the price of less parsimony and other potential misspecification problems related to assumptions about the timing of investment decisions and about the moment when newly hired capital becomes productive.

The main limitation concerns the small number of cross-sections available to estimate the model. This limits the scope of the results, because estimates of the parameters may depend strongly on the aggregate phenomena that occurred in the sample period. Only the availability of data for additional periods can clarify this question.

\section{Acknowledgements}

I thank Víctor Aguirregabiria, Samuel Bentolila, Richard Blundell, Steve Bond, Dolores Collado, Juan Dolado, José E. Galdón, José Méndez, Ana Munera, and very especially, Manuel Arellano, for valuable advice and helpful comments. This paper also benefited from presentations at FEDEA, Fundación Empresa Pública

\footnotetext{
12 Hamermesh (1993a) suggests that use of temporally aggregated data can only offer smooth approximations to the underlying structure of adjustment costs.
} 
and Universidad Carlos III, and the useful suggestions of an anonymous referee and a co-editor of this journal. An earlier version of this paper was presented at the EEA Conference in Prague, August 1995. I also thank the staff of the Central de Balances del Banco de España for providing the raw data. Research funding from a CEMFI Ph.D. scholarship and from the Spanish DGES, Grant PB95-0292, is also acknowledged.

\section{Appendix A. Data description}

The CBBE data set is a balanced panel of 1080 Spanish non-energy, manufacturing companies, with a public share lower than 50 percent, recorded in the database of the Bank of Spain's Central Balance Sheet Office. Although this database contains firm-level information on the balance sheets, employment, and other complementary information for a large number of manufacturing companies since 1982, disaggregated data on employment are reported only since 1986. I have thus selected those firms that remained in the sample during 1986-1991, and satisfied several coherency conditions. All companies with non-positive values for net worth, capital stock, accumulated and accounting depreciation, labour costs, employment, sales, output, or whose book value of capital stock jumped by a factor greater than 3 from one year to the next, were dropped from the sample. The variables are described as follows:

\section{A.1. Employment}

Number of employees is disaggregated into permanent white collar, permanent blue collar and temporary employees. Permanent white collar employment is also disaggregated into four occupations: managerial, professional, commercial and clerical. To maintain measurement consistency, the number of temporary employees is calculated in annual terms by multiplying the number of temporary employees along the year times the average number of weeks worked by temporary employees and divided by 52 .

\section{A.2. Real wages}

The measure of the firm's annual average labor costs per employee $W_{i t}$ is computed as the ratio of Total wages and salaries to Total number of employees. This measure was deflated using Retail Price Indices for each of the industries of manufacturing sector. (Source: National Statistics, hereinafter INE). Computation of average wages per type of worker is done using information on wages of nonproduction and production employees at industry level from Encuesta de Salarios and on wages of permanent and temporary employees at industry level from Distribución de Salarios (source: INE). 
The wage for temporary employees is computed as $W_{i t}^{T}=W_{i t}\left(L_{i t}^{T}+L_{i t}^{P}\right)\left(L_{i t}^{T}+\right.$ $L_{i t}^{P} \mu_{i t}^{P, T}$ ), where, for period $t, L_{i t}^{T}, L_{i t}^{P}$ are the average annual number of temporary employees and the number of permanent employees in the firm, respectively, and $\mu_{i t}^{P, T}$ is the wage margin of permanent employees with respect to temporary employees (obtained at the industry level from Distribución de Salarios). The wage of permanent employees is thus $W_{i t}^{P}=\mu_{i t}^{P, T} W_{i t}^{T}$. The wage for permanent production or blue collar employees can be computed as $W_{i t}^{P b}=\left(W_{i t}^{P} L_{i t}^{P}\right) /\left(L_{i t}^{P b}+\right.$ $\left.L_{i t}^{P w^{w}} \mu_{i t}^{b, w}\right)$, where, for period $t, L_{i t}^{P b}$ and $L_{i t}^{P w}$ are the number of permanent production (blue collar) employees and permanent nonproduction (white collar) employees, respectively, and $\mu_{i t}^{b, w}$ is the wage margin of nonproduction employees with respect to production employees (obtained at the industry level from Encuesta de Salarios). Finally, the wage of permanent white collar employees is computed as $W_{i t}^{P w}=\mu_{i t}^{b, w} W_{i t}^{P b}$.

\section{A.3. Output}

Gross output at retail prices is calculated as total sales, plus the change in finished product inventories and other income from the production process, minus taxes derived on the production (net of subsidies).

\section{A.4. Fixed capital}

I am interested in investment in depreciable fixed capital which is already productive, so Land and Capital stock in course of construction are excluded from the definition of the stock of fixed capital. Since the CBBE does not have independent estimates of investment available, gross nominal investment $I_{i t}$ must be imputed from changes in the book value of fixed capital with a correction for depreciation, that is $I_{i t}=\mathrm{KNB}_{i t}-\mathrm{KNB}_{i, t-1}+\mathrm{Dep}_{i t}+\mathrm{Rev}_{i t}$ where, $\mathrm{KNB}_{i t}=$ $\mathrm{KGB}_{i t}-\mathrm{ADep}_{i t}$ is the book value of the net stock of fixed capital (book value of the gross stock of fixed capital $\mathrm{KGB}_{i t}$ minus accumulated depreciation $\mathrm{ADep}_{i t}$ ); $\operatorname{Dep}_{i t}$ is the accounting depreciation during the year; and $\operatorname{Rev}_{i t}$ is the net variation in the book value of fixed capital and in its accumulated depreciation due to positive and/or negative revaluations.

To calculate the replacement value of capital, I use a perpetual inventory method which takes account for depreciation and inflation. To do this, an initial value for the first year that data are available for a given firm is calculated

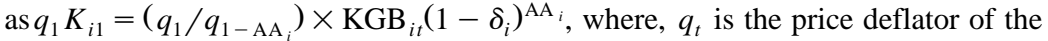
stock of fixed capital, $\delta_{i}$ is the average depreciation rate of the stock of fixed capital, and $\mathrm{AA}_{i}$ is the average age of the stock of fixed capital. The average age is approximated by the ratio $\mathrm{ADep}_{i 1} / \mathrm{Dep}_{i 1}$ for the first year in which data for the firm are available. Furthermore, the average depreciation rate is computed at the firm level as the ratio of the firm's average accounting depreciation to the firm's average accumulated depreciation. As regards price indices, the corresponding 
GDP implicit deflator of investment goods is used (source: INE). The recursive method to compute the replacement value of the stock of fixed capital from the second year that data are available is $q_{i t} K_{i t}=\left(q_{i t} / q_{i, t-1}\right) K_{i, t-1}\left(1-\delta_{i}\right)+I_{i t}$, which assumes that investment occurs at the end of the year. The recursive method employed here can generate negative market values $q_{t} K_{t}$, or market values significantly above zero when the book value of fixed capital is zero. This fact is taken into account to eliminate firms with implausible values for the stock of fixed capital.

\section{A.5. Interest rates}

To compute the discount rate, I use the long-term interest rate on electricity company bonds (source: Bank of Spain). The real rate of return is computed deflating the nominal rate of return by the corresponding Retail Price Index at the two-digit industry classification (source: INE).

\section{References}

Amemiya, T., 1984. Tobit models: a survey. Journal of Econometrics 24, 3-61.

Andrés, J., García, J., 1991. Una interpretación de las diferencias salariales entre sectores. Investigaciones Económicas 15, 143-167.

Bentolila, S., Dolado, J.J., 1994. Labour flexibility and wages: lessons from Spain. Economic Policy 18, 53-99.

Blanchard, O., Jimeno, J.F., Andrés, J., Bean, C., Malinvaud, E., Revenga, A., Saint-Paul, G., Snower, D.J., Solow, R., Taguas, D., Toharia, L., 1995. Spanish unemployment: is there a solution? Report from the Centre for Economic Policy Research, London.

Bresson, G., Kramarz, F., Sevestre, P., 1991. Labour demand for heterogeneous workers with non linear asymmetric adjustment costs. INSEE, W.P. No. 1924.

Bresson, G., Kramarz, F., Sevestre, P., 1992. Heterogenous labour and the dynamics of aggregate labour demand: some estimations using panel data. Empirical Economics 17, 153-168.

Burda, M.C., 1991. Monopolistic competition, costs of adjustment, and the behavior of European manufacturing employment. European Economic Review 35, 61-79.

Griliches, Z., Mairesse, J., 1998. Production functions: the search for identification. In: Griliches, Z. (Ed.), Practicing econometrics: essay in method and application. Edward Elgar, London.

Groshen, E.L., 1991. Sources of intra-industry wage dispersion: how much do employers matter?. Quarterly Journal of Economics 106, 869-884.

Hamermesh, D.S., 1993a. Spatial and temporal aggregation in the dynamics of labour demand. In: van Ours, J., Pfann, G., Ridder, G. (Eds.), Labour demand and equilibrium wage formation. North-Holland, Amsterdam.

Hamermesh, D.S., 1993b. Labor Demand. Princeton University Press, Princeton, NJ.

Hamermesh, D.S., Pfann, G.A., 1996. Adjustment costs in factor demand. Journal of Economic Literature 34, 1264-1292.

Nadiri, I., Rosen, S., 1969. Interrelated factor demand functions. American Economic Review 59, 457-471.

Ogaki, M., 1993. Generalized method of moments: econometric applications. In: Maddala, G.S., Rao, C.R., Vinod, H.D. (Eds.), Handbook of Statistics, Vol. 11, Econometrics. North-Holland, Amsterdam. 
Palm, F.C., Pfann, G.A., 1990. Interrelated demand rational expectations models for two types of labour. Oxford Bulletin of Economics and Statistics 52, 45-68.

Pfann, G.A., Palm, F.C., 1993. Asymmetric adjustment costs in non-linear labour demand models for the Netherlands and the UK manufacturing sectors. Review of Economic Studies 60, 397-412.

Pfann, G.A., Verspagen, B., 1989. The structure of adjustment costs for labour in the Dutch manufacturing sector. Economics Letters 29, 365-371.

Pindyck, R.S., Rotemberg, J.J., 1983. Dynamic factor demands under rational expectations. Scandinavian Journal of Economics 85, 223-238.

Rota, P., 1997. Dynamic labour demand with fixed adjustment costs. Unpublished paper, University College, London.

Sanz Gómez, M.C., 1993. Una estimación de la demanda de trabajo manual y no manual. Investigaciones Económicas 18, 333-364.

Sargent, T.J., 1978. Estimation of dynamic labor demand schedules under rational expectations. Journal of Political Economy 86, 1009-1044.

Segura, J., Durán, F., Toharia, L., Bentolila, S., 1991. Análisis de la contratación temporal en España. Colección Economía y Sociología del Trabajo No. 47. Ministerio de Trabajo y Seguridad Social, Madrid, Spain.

Stoker, T.M., 1991. Lectures on semiparametric econometrics. CORE Lecture Series, Core Foundation, Universite Catholique de Louvain, Louvain-la-Neuve, Belgium. 